\title{
THE USE OF TITANIUM MESH COATED WITH HYDROXYAPATITE NANOCRYSTALS IN MANDIBULAR FRACTURE (EXPERIMENTAL STUDY)
}

\author{
Asmaa M. Ezzat ${ }^{l} B D S$, Abdel Aziz F. Khalil ${ }^{2} P h D$, Riham M. El-Dibany² $P h D$,
}

Nesma M. Khalil ${ }^{3} P h D$

\begin{abstract}
INTRODUCTION: Comminuted fractures of the mandible are an important traumatism, in which the mandibular bone is splintered or crushed. Treatment of these types of fractures had always been a challenge to surgeons, considering both the severity of the trauma and the presence of discontinuity defects which require replacement and augmentation in order to treat the bone loss. Titanium mesh was proved to be particularly useful for reconstruction of mandibular discontinuity defects also it can be used as a scaffold for bone grafts. Electrophoretic deposition (EPD) is a coating technique used to increase the osseointegration and increases bone regeneration.

OBJECTIVES: To histologically evaluate the effect of titanium mesh coated with hydroxyapatite nanocrystals using electrophoretic deposition on bone osseointegration and healing following comminuted mandibular fractures.

MATERIALS AND METHODS: A controlled induced comminuted fracture on the inferior border of the mandible extending from the $2^{\text {nd }}$ premolar to the $2^{\text {nd }}$ molar was performed on 12 mongrel dogs. Six dogs were treated using titanium mesh coated with hydroxyapatite nanocrystals (study group) and the other six using uncoated titanium mesh (control group). The dogs were sacrificed at 2, 4 and 6 weeks and the specimens were dissected to be histologically and radiographically evaluated for new bone formation.

RESULTS: The histological outcome showed superior bone healing in the bony defects in the resembling comminuted fracture in the study group than the control group.

CONCLUSIONS: The nano-hydroxyapatite coated titanium mesh is a suitable method for reconstruction of comminuted fractures with bony defects.

KEYWORDS: titanium mesh, hydroxyapatite nanocrystals, electrophoretic deposition, comminuted fracture, mandibular farcture.

1- Bachelor of Dentistry, BDS, Faculty of Dentistry, Alexandria University, Alexandria, Egypt.
2- $\quad$ Professor of Oral and Maxillofacial Surgery, BDS, MSc, PhD, Faculty of Dentistry, Alexandria University, Alexandria, Egypt.
3- $\quad$ Lecturer of Oral Biology, BDS, MSc, PhD, Faculty of Dentistry, Alexandria University, Alexandria, Egypt.
\end{abstract}

\section{INTRODUCTION}

Mandibular fractures have a high incidence because of the mandible's prominence and relative lack of support. They present a unique problem to the oral surgeon and necessitate prompt treatment. In some cases of mandibular fractures, bone defects may be present which require replacement and augmentation in order to treat the bone loss $(1,2)$.

Comminuted mandibular fractures result from a significant impact to a localized area of the oromandibular complex, in which the mandibular bone is splintered, crushed, pulverized, or broken into several pieces (3). Finn (4) earlier defined comminution as the presence of multiple fracture lines creating many small pieces of bone in the same region of the mandible (i.e. the angle, body, ramus, or symphysis). After assessing and stabilizing any lifethreatening condition, careful clinical assessment of the oromandibular complex is essential (3-5).

In comminuted fractures it was found that closed reduction is extremely difficult. The fragments must be exactly reduced, and the plate must be adapted exactly (6), and this was found to be quite tedious and require great precision. So, titanium mesh which is one of the methods of treatment of comminuted fractures proved to be particularly useful for reconstruction of mandibular discontinuity defects. It permits functionally and aesthetically satisfactory restoration of bony continuity regardless of size or site of the defect (7-9).
Hydroxyapatite is a bioactive material that has shown the ability for better bone bonding due to formation of a surface calcium phosphate layer in contact with biological fluids (10). Pure HA has poor mechanical properties, hence, it has been used as coatings on the surface of metallic materials in order to combine the strength and toughness of the substrate with the bioactivity of HA. It has also been suggested that the application of HA coatings will improve corrosion resistance of metal and reduce metallic ion release at the same time as promoting its bone bonding ability (11-15).

Nanocrystalline hydroxyapatite bone graft has been introduced for augmentation procedures in intrabony defects. Its advantages are osteoconductivity, bioresorbablity, and close contact. Typical description of materials with nanostructures is a very high number of molecules on the surface of the material. When used as a bone graft substitute, rapid healing of critical size defects was observed in animal experiments and in human applications (16). HA nanocrystals binds to bone and stimulates bone healing by stimulation of osteoblast activity. It has been used in ridge augmentation, and periimplantitis (17-19).

Many coating techniques have been investigated in order to deposit HA nanocrystals on the surface of metallic substrates including plasma spraying, sol-gel, ion beam dynamic mixing and pulse laser deposition. However, there are many limitations in such techniques which include nonuniform coating formation over geometrically complex 
surfaces, thermal decomposition of HA during the high temperature process, sluggishness of the process, low crystallinity and poor adhesion of the coating on the substrates (15). Therefore, there has been an increasing interest in the application of other techniques in recent years, such as, electrophoretic deposition (EPD) process (15).

EPD is a rapid and inexpensive method that exhibits some advantages over the alternative processes. Some of these advantages are simplicity of the method, high reproducibility, control over the thickness of the coating, low temperature, ability to produce a composite layer and finally applicability for medical purposes $(20,21)$. EPD is used in surgery mostly in coating of titanium substrates using $\mathrm{HA}$ as titanium implants to increase the osseointegration and contact between bone and the implant, also it was found to coat titanium plates with HA which provide more biocompatibility of titanium plates and increases bone regeneration (20).

Although many researchers studied the effect of electrophoretic deposition of HA on titanium plates $(10,12,20)$ and titanium implants $(21)$ no researches were found on its effect on titanium mesh. Therefore, this study was designed to evaluate the effect of coating of titanium mesh by hydroxyapatite nanocrystals using electrophoretic deposition in an induced mandibular fracture.

\section{MATERIALS AND METHODS}

This experimental study was conducted on 12 mongrel dogs; (1-2 years of age) and (10-12 Kg) in weight. The animals were kept under proper nutritional and environmental conditions in the animal house of the Medical Research Institute (MRI), Alexandria University. They were examined by the animal house veterinarian to exclude any disease and were kept on the same balanced diet consisting of milk and broth throughout the whole period.

Dogs were divided into a study group which included six dogs, where they received a titanium mesh coated with hydroxyapatite nanocrystals for the treatment of an induced triangular comminuted mandibular fracture. The control group included six dogs that received an uncoated titanium mesh for the treatment of an induced triangular comminuted mandibular fracture of $2 \mathrm{~cm}$ height and $3.5 \mathrm{~cm}$ width extending from the $2^{\text {nd }}$ premolar to the $2^{\text {nd }}$ molar.

The Ethical committee of Alexandria University approved the protocol of this research. The guidelines for the care and use of experimental animals according to the institution in which the work was done were followed.

\section{Preparation of the titanium mesh:}

The titanium mesh was coated with hydroxyapatite nanocrystals at the Chemistry Laboratories, Faculty of Engineering, Alexandria University using electrophoretic deposition (EPD) and the natural nano-hydroxyapatite was prepared in the Biomaterial Department, National Research Center, Cairo Egypt.

Commercially available titanium mesh of thickness $1 \mathrm{~mm}$ were cut to a triangular shape of $2.5 \mathrm{~cm}$ height and $4 \mathrm{~cm}$ width. The titanium mesh was cleaned with ethanol. After the cleaning process, the plates were immersed in pure butanol (El-Nasr pharmaceutical chemical company, Alexandria Egypt) for 24 hours. A 5\% (wt/wt) suspension was prepared from natural nano-hydroxyapatite.
The natural nanohydroxyapatite ranged from 10-60 nm and porosity $60-80 \% .5 \mathrm{~g}$ nano-hydroxyapatite was mixed with pure butanol. The suspension was ultrasonicated for one hour to avoid air bubbles. The EPD process was performed in a glass beaker equipped with a holder to fix the electrodes. The platinum counter electrode and titanium samples were used as anode and cathode, respectively.

The coated titanium mesh was sintered in a ventilated oven at $1000^{\circ} \mathrm{C}$ for 6 hours, then the samples were surface characterized using scanning electron microscope (SEM). The samples were sterilized in the Nuclear energy organization, Cairo, by gamma radiation at $2.5 \mathrm{M}$ rad before using the samples in our study. (Fig.1)

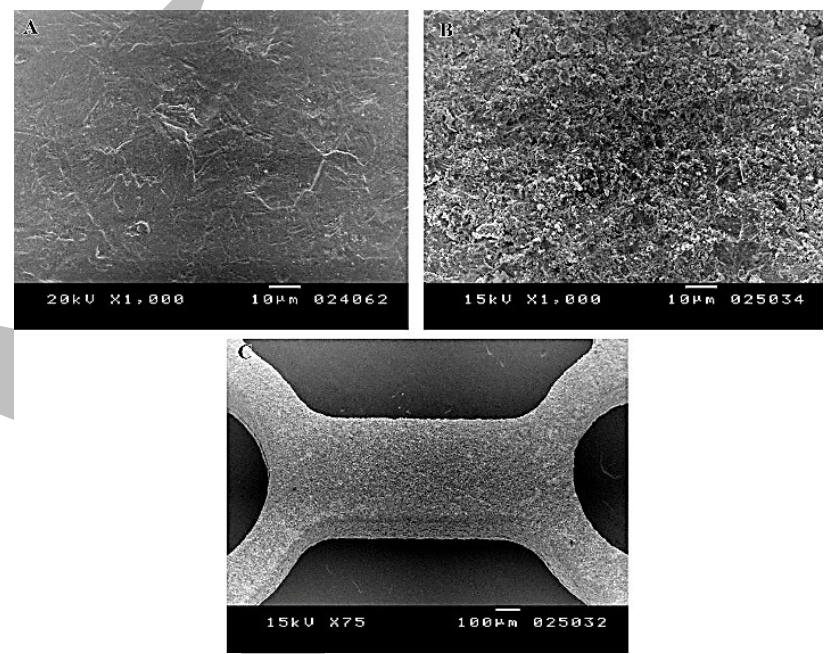

Figure 1: (A) A photograph showing electron microscope scanning of uncoated titanium mesh. (B) A photograph showing electron microscope magnification $1,000 \mu \mathrm{m}$ of coated hydroxyapatite nanocrystals. (C) A photograph showing the electron microscope scanning of the coated titanium mesh.

\section{Pre-operative phase:}

The animals were starved for 12 hours and thirsted for 6 hours prior to anesthesia. Each animal received a dose of ampicillin $25 \mathrm{mg} / \mathrm{kg}$ body weight (Epicocillin, provided by: Eipico Pharmaceutical Co., 10th of ramadan city, Cairo Egypt) just before the operation to control post-operative infection.

\section{Surgical procedure:}

All dogs received general anesthesia using intravenous injection of thiopentone sodium (Pentothal, provided by: Glazer Exports Co. Dinshaw Waschha,India) 5\% in a dose of $30 \mathrm{mg} / \mathrm{kg}$ body weight. Injection of the anesthetic drug was performed after aspiration to assure correct identification of the femoral vein via an 18-gauge medical cannula.

For all the experimental animals, a unilateral submandibular skin incision was performed measuring about $4 \mathrm{~cm}$ in length and one finger below and parallel to the lower border of the mandible, using Bard Parker scalpel handle no.3 and disposable blade No.10. Bone was exposed through careful blunt dissection of soft tissues.

An acrylic template was used to define the borders of the artificial fracture. An artificial triangular fracture extending from the $2^{\text {nd }}$ premolar to the $2^{\text {nd }}$ molar was created in the buccal aspect of the mandible at the level of the inferior border using a surgical bur.(Fig.2) The defect was created by removing the buccal cortex with dimensions of $2 \mathrm{~cm}$ height and $3.5 \mathrm{~cm}$ width. After the triangular defect was 
prepared, the buccal plate of the mandibular bone was removed using an osteotome then crushed into pieces using a bone rongeur. Finally, the fractured parts were reassembled in the defect resembling a comminuted fracture with bony defects.

In the Study group the titanium mesh coated with hydroxyapatite nanocrystals was fixed using 2 screws of $7 \mathrm{~mm}$ long. In the control group the uncoated titanium mesh was fixed using 2 titanium screws of $7 \mathrm{~mm}$ long All the surgical sites were closed in layers using 3-0 vicryl (Resorbable suture material by Johnson \& Johnson Int., CO Center, Belgium) suture material for the deep layers, and 3/0 black silk suture for the skin incision. (Fig.3)
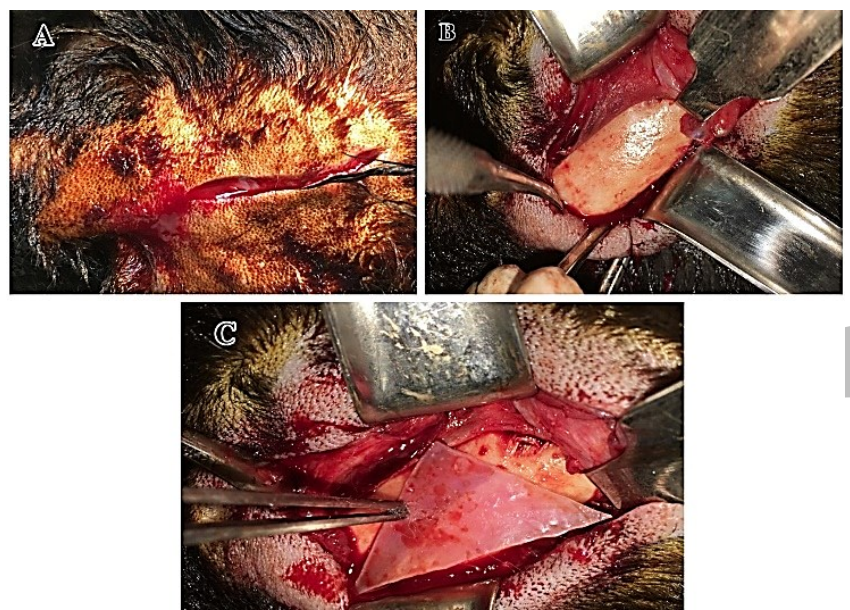

Figure 2: (A) A photograph showing unilateral submandibular skin incision (B) A photograph showing exposed bone of the mandibular region (C) A photograph showing the use of the acrylic template to define the borders of the fracture.
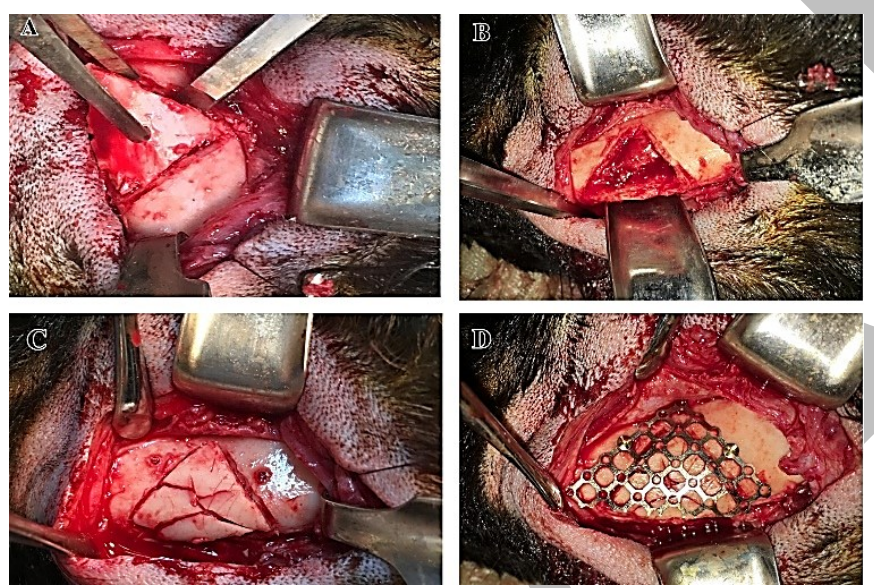

Figure 3: (A) A photograph showing the use of osteotome in removal of the buccal plate of bone (B) A photograph showing the mandibular defect made after removal of the cortical plate of bone (C) A photograph showing reassembling the fractured bone into a comminuted fracture (D) A photograph showing placement of titanium mesh.

\section{Post-operative phase:}

After the surgical procedure, each animal received the same course of antibiotics of ampicillin $25 \mathrm{mg} / \mathrm{kg}$ body weight for five days every eight hours. Ketorolac tromethamine (ketolac by El-Amryia Company- Alexandria, Egypt) $1 \mathrm{mg} / \mathrm{kg}$ subcutaneous injection every 24 hours was given as an analgesic and anti-inflammatory drug to the animals for 3 days post-operatively.Glucose water was given to the animals on the first post-operative day. Then the animals were kept on soft diet consisting of bread, milk and broth on the first four weeks post-operatively.

\section{Histological specimens:}

Two specimens from each group were harvested 2, 4 and 6 weeks from the initial surgery. The site of bone fractures was resected en bloc to be prepared for histologic examination. The preparation of the undecalcified histological sections was performed.

\section{RESULTS}

\section{Clinical results:}

Clinically the dogs showed normal healing of the incision without any infection, dehiscence or any other complication. Also, the dogs showed normal activity and normal feeding habits.

\section{Histological results:}

\section{After two weeks:}

Histological examination of specimens obtained from the control group revealed woven bone formation with many spicules filling the fracture site and osteocytes lacunae were seen in large numbers and irregularly arranged. In the study group, two outstanding observations were noted. The first one was the thickness of the newly formed bone trabeculae which appeared relatively thick in comparison to those of the control group. The second observation was the homogenous mineralization of the newly deposited bone matrix.

\section{After four weeks:}

In the 4 weeks' specimens no major difference was found as both the study group and the control group showed formation of cancellous bone trabeculae enclosing bone marrow of different sizes, also osteocyte lacunae were found with relatively regular distribution in some specimens and irregular distribution in others.

\section{After six weeks:}

The 6 weeks' control group specimens showed cancellous bone formation, while in the 6 weeks' study group, some specimens showed mature lamellar bone formation, dense cancellous bone trabeculae enclosing bone marrow spaces of different sizes and in some of the 6 weeks' study specimens dense compact bone in the fracture defect areas was found and the dense compact was found having centrally located Haversian canals and concentric lamellae. (Fig. 4-6)

\section{DISCUSSION}

Reconstruction of maxillofacial continuity defects has always been a challenging task for the scientists and surgeons over the years. The main goal of the reconstruction of the maxillofacial region is to restore facial form, function, full rehabilitation of occlusion and articulation (22).

The present study was conducted to compare the effect of titanium mesh coated with hydroxyapatite nanocrystals and uncoated titanium mesh on bone healing of surgically created osseous defects in dogs. The dogs were divided equally into two groups; a control group, where osseous defects resembling a comminuted fracture were created and stabilized using uncoated titanium mesh, while in the study group, the created comminuted fractures were stabilized using titanium mesh coated with hydroxyapatite nanocrystals.

Titanium mesh was used in this study for stabilization of comminuted fractures. This follows the study conducted by 
Patel and Langdon in 1991 (23), where they stated that the use of titanium mesh to treat comminuted fractures has proved itself invaluable. The mesh can be placed transorally or extra-orally depending on the size and shape of the mesh and the degree of comminution of the bone, it has excellent biocompatibility and generates minimal inflammatory reaction (24).
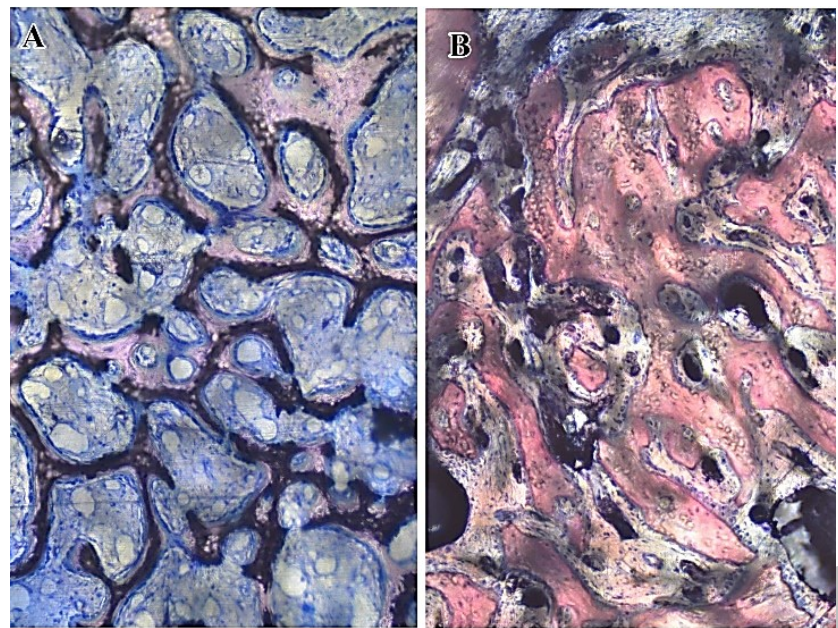

Figure 4: (A) LM high magnification of 2 weeks control group showing the newly formed woven bone spicules with dark hypomineralization core, bone spicules lined by osteoid and a continuous layer of osteoblasts (B) LM high magnification of 2 weeks study group showing trabeculae of the newly formed bone with high osteocyte content. A continuous layer of active osteoblast cells is seen on the outer surface of the bone trabeculae. Note the thickness of the newly formed trabeculae and its relatively homogeneous degree of mineralization.
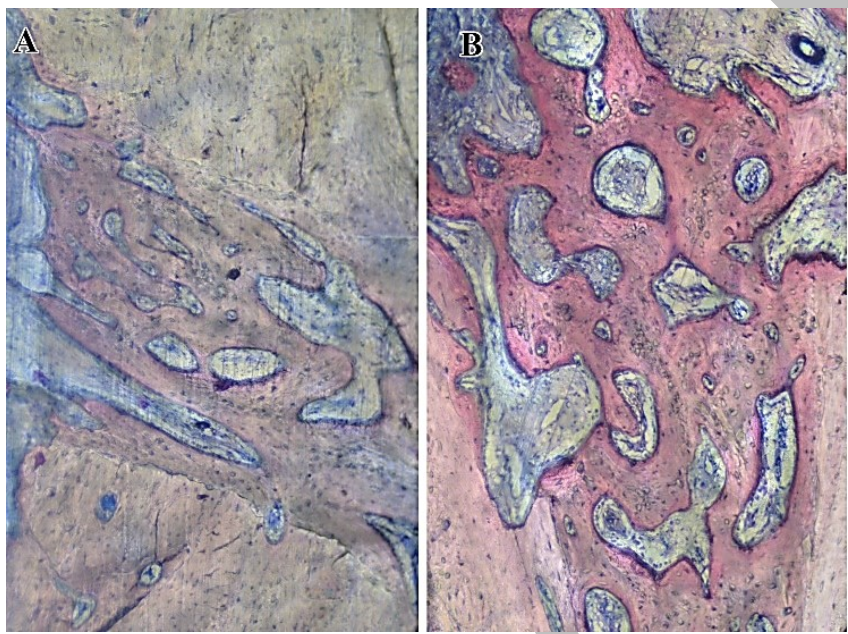

Figure 5: (A) LM high magnification of 4 weeks control group showing the density of the newly formed cancellous bone trabeculae with relatively regularly arranged osteocyte lacunae. A line of demarcation can be seen between the native and newly formed bone. (B) LM high magnification of 4 weeks study group showing the organization of the newly formed trabeculae which appear relatively thick and surround numerous bone marrow spaces. Osteoblasts can be seen lining the endosteal surface of the trabeculae.

Although titanium (Ti) and its alloys is the most widely used material in dentistry, their good biocompatibility, good resistance to corrosion, excellent mechanical properties, and workability, are their main advantages (25), but one of its main disadvantages is its disability to create a bond between it and the living host tissue (26).
So, one of the major innovations in bone reconstruction in the past 30 years has been applying HA as a surface coating on mechanically strong metallic implants such as titanium implants and its alloys, in an attempt to improve bone fixation to the implant (27).

Two studies performed by Gotz et al (28) in 2010 and Gerber et al (29) in 2012 regarding HA nanocrystals reported that the nano-hydroxyapatite has been used as an additive material, in order to improve already existing and widely used dental materials, in the restorative field, because of its unique properties, such as the ability to chemically bond to bone, to not induce toxicity or inflammation and to stimulate bone growth through a direct action on osteoblasts, nano-HA has been widely used in periodontology and in oral and maxillofacial surgery.

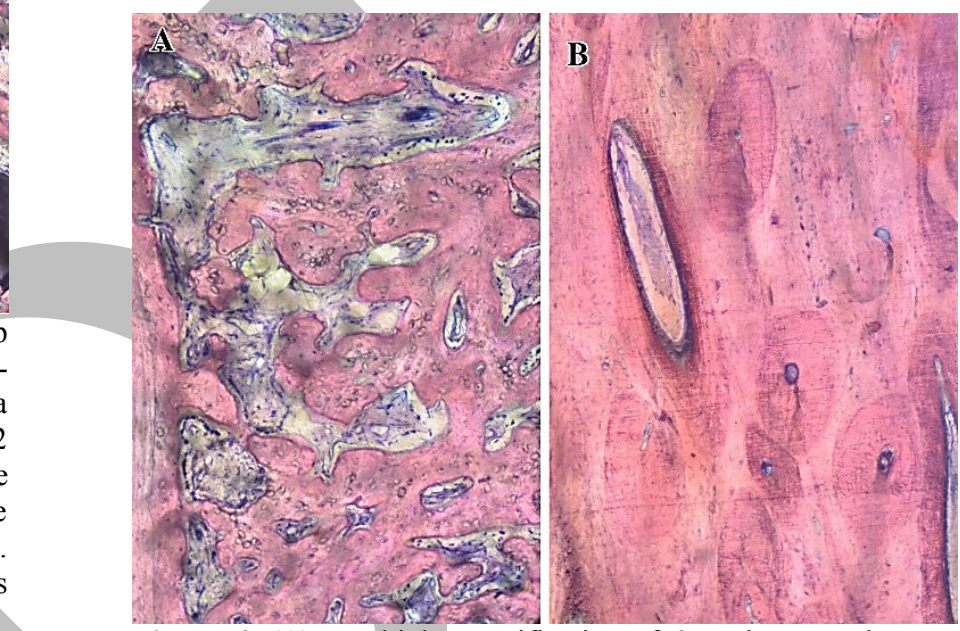

Figure 6: (A) LM high magnification of 6 weeks control group showing the structure of the healing bone with relatively irregularly distributed osteocyte lacunae (B) LM high magnification of 6 weeks study group showing the density of the formed compact bone and its structural units of small haversian systems.

Electrophoretic deposition (EPD) was the coating method of choice as it has some advantages over other techniques as reported by Boccaccini et al in 2010 (30), including its short coating time (2-3 min), high reproducibility, repeatable, inexpensive and ensure rapidity of the process. This technique additionally enables controlling the coating thickness, its uniformity and deposition rate.

According to Lacefield in 1998 (31) and Sena et al in 2002 (32) coating of biologically inert metallic implants with biologically active materials, like hydroxyapatite, attempts to accelerate bone formation on initial stages of osseointegration, thus improving implant fixation. HA deposition by electrophoresis was described by Ducheyne and Qiu in 1999 (33) as the best technique to coat irregular surfaces.

The general outcome of this study was superior and faster bone healing and osteoblastic activity in the study group than in the control group. Also, there were no signs of infection, abnormal reaction or wound dehiscence in any of the dogs.

The histologic evaluation showed a definite difference between the 2 and 6 weeks' specimens of both the study and control groups, while in the 4 weeks' specimens the study and control groups showed no major differences between them. 
These results are in accordance with Manjubala, et al in 2005 (34), where they reported that complete Haversian system was observed after 12 weeks in a dog model. Therefore, finding the Haversian system after 6 weeks' study group proved that the HA nanocrystals coated titanium mesh placed in the resembling comminuted fracture in the experimental model accelerated and promoted healing of osseous defects by forming new bone through their osteoconductive and osteoinductive properties. These histological results proved that nanohydroxyapatite coated titanium mesh can be considered as an appropriate reconstructive and bone substitute material, and it can promote bone regeneration in bone defects due to its osteoconductive properties.

These results agreed with Yang et al (35) in 2010. They investigated bone formation on titanium implant surfaces coated with biomimetically deposited calcium phosphate (BDCaP) or electrochemically deposited hydroxyapatite (EDHA). Their histologic observation showed that new bone on the EDHA-coated implant became mature after 4 weeks, while new bone on the control and BDCaP-coated implants was mature after 8 weeks.

Finally, the formation of bone cells and the trabecular bone is an indication of the osteoconductivity of the material. It may be inferred that new osteoblast cells directly proliferating, differentiating, and creeping into the surface of the material filling the defect as an indication of osteoconduction and bonding them chemically to complete biological integration between materials and the existing bone.

\section{CONCLUSIONS}

This study demonstrated complete bone regeneration of comminuted fracture defects using titanium mesh coated with nano-hydroxyapatite by electrophoretic deposition after 6 weeks.

\section{CONFLICT OF INTEREST}

The authors declare that they have no conflict of interest.

\section{ACKNOWLEDGEMENT}

The authors want to acknowledge Dr. Yasser El-Kamary and Dr. Mohamed Farouk Mekky for their scientific contribution in this study.

\section{REFERENCES}

1. Thorén H, Iso-Kungas P, Lizuka T, Lindqvist C, Törnwall J. Changing trends in causes and patterns of facial fractures in children. Oral Surg Oral Med Oral pathol Oral Radiol Endod. 2009; 107:18-24.

2. Lee KH. Epidemiology of mandibular fractures in a tertiary centre. Emerge Med J. 2008; 25:565-8.

3. Ellis E 3rd, Muniz O, Anand K. Treatment considerations for comminuted mandibular fractures. J Oral Maxillofac Surg. 2003; 61:861-70.

4. Finn RA. Treatment of comminuted mandibular fractures by closed reduction. J Oral Maxillofac Surg. 1996; 54:320 7.

5. Futran ND. Management of comminuted mandible fractures. J Otolaryng Head Neck Surg. 2008; 19:113-6.

6. Chrcanovic BR. Open versus closed reduction: comminuted mandibular fractures. Oral Maxillofac Surg. 2013 ;17(2):95-104.
7. Lee K, Yoon K, Park KS, Cheong J, Shin J, Bae J, Ko I, Park H. Treatment of extensive comminuted mandibular fracture between both mandibular angles with bilateral condylar fractures using a reconstruction plate: a case report. J Korean Assoc Oral Maxillofac Surg. 2014 ;40(3):135-9.

8. Warraich R, Rashad A, von See C, Channar KA, Rana M, Stoetzer $\mathrm{M}$, et al. Management of comminuted but continuous mandible defects after gunshot injuries. Injury. 2014;45(1):206-11.

9. Paul SA, Karthik AK, Chacko R, Karunya W. Audit on titanium reconstruction of mandibular defects for jaw lesions. J Pharm Bioallied Sci. 2014;6(1): S39-S43.

10. Basle MF, Lesourd M, Grizon F, Pascaretti C, Chappard D. Type I collagen in xenogenic bone material regulates attachment and spreading of osteoblasts over the betal integrin subunit. Orthopade. 1998; 27:136-42.

11. Christopher J, Damien J, Russell Parsons. Bone graft and bone graft substitutes: A review of current technology and applications. J Appl Biomater. 1991;2(3):187-208.

12. Peter SJ, Miller MJ, Yasko AW, Yaszemski MJ, Mikos AG. Polymer concepts in tissue engineering. J Biomed Mater Res. 1998;43(4):422-7.

13. Maruthmuthu K, Thomas S, Muniapillai S. Efficacy of Chitra granules (porous hydroxyapatite crystals) as an alloplastic bone graft. J Indian Acad Dent Spec Res. 2014; $1: 15-21$.

14. Movassaghi K1, Ver Halen J, Ganchi P, Amin-Hanjani S, Mesa J, Yaremchuk MJ. Cranioplasty with subcutaneously preserved autologous bone grafts. Plast Reconstr Surg. 2006 ;117(1):202-6.

15. Manara S, Paolucci F, Palazzo B, Marccoio M. Electrochemically assisted deposition of biomimetic hydroxyapatite-collagen coatings on titanium plates. Inorganica chimica Acta. 2008; 361:1634-45.

16. García-Sanz FJ, Mayor MB, Arias JL, Pou J, León B, PérezAmor M. Hydroxyapatite coatings: a comparative study between plasma spray and pulsed laser deposition techniques. J Mater Sci Med. 1997; 8(12):861-5.

17. Kwok C, Wong P, Cheng F, Man H. Characterization and corrosion behavior of hydroxyapatite coatings on Ti6Al4V fabricated by electrophoretic deposition. Appl Surf Sci. 2009; 255:6736-44.

18. Javidi M, Javadpour S, Bahrololoom M, Ma J. Electrophoretic deposition of natural hydroxyapatite on medical grade 316L stainless steel. Mater Sci Eng. 2008; 25:1509-15.

19. Stoch J, Brozek A, Kmita G, Stoch J, Jasterzebki W, Rakowsa A. Electrophoretic coating of hydroxyapatite on titanium implants. J Mol 2001; 569:191-200.

20. Tahmasbi A, Solati-Hashjin M, Osman N, Faghihi S. Improved bio-physical performance of hydroxyapatite coatings obtained by electrophoretic deposition at dynamic voltage. International Ceramics.2014;40:12681-91.

21. Schnettler R, Alt V, Dingeldein E, Pfefferle HJ, Kilian O, Meyer $\mathrm{C}$, Heiss $\mathrm{C}$, Wenisch $\mathrm{S}$ Bone ingrowth in bFGFcoated hydroxyapatite ceramic implants. Biomaterials. 2003; 25: 4603-8.

22. Rana M, Warraich R, Kokemüller H, Lemound J, Essig H, Tavassol F, et al. Reconstruction of mandibular defects clinical retrospective research over a 10-year period. Head Neck Oncol 2011; 3: 23. 
23. Patel MF, Langdon JD. Titanium mesh (TiMesh) osteosynthesis: a fast and adaptable method of semi-rigid fixation. J Oral Maxillofac Surg 1991; 29: 316-24.

24. Lakhani RS, Shibuya TY, Mathog RH, Marks SC, Burgio DL, Yoo GH. Titanium mesh repair of the severely comminuted frontal sinus fracture. Arch Otolaryngol Head Neck Surg 2001; 127: 665-9.

25. Bigi A, Boanini E, Bracci B, Facchini A, Panzavolta S, Segatti F, et al. Nanocrystalline hydroxyapatite coatings on titanium: a new fast biomimetic method. J Bio mater 2005;26(19):4085-9.

26. Suchanec W, Yoshimura M. Processing and properties of hydroxyapatite-based biomaterials for use as hard tissue replacement implants. J Mater Res 1998; 13: 94-117.

27. Ducheyne P, Hench LL, Kagan A, Martens M, Bursens A, Mulier JC. Effect of hydroxyapatite impregnation on skeletal bonding of porous coated implants. J Biomed Mater Res 1980; 14: 225-37.

28. Götz W, Lenz S, Reichert C, Henkel KO, Bienengräber V, Pernicka L, et al. A preliminary study in osteoinduction by a nano-crystalline hydroxyapatite in the mini pig, Folia Histochem Cytobiol 2010; 48: 589 -96.

29. Gerber T, Lenz S, Holzhüter G, Götz W, Helms K, Harms C, et al. Nanostructured Bone Grafting Substitutes - A Pathway to Osteoinductivity. Key Eng Mater 2012; 493 494: 147-52.

30. Boccaccini AR, Keim S, Ma R, Li Y, Zhitomirsky I. Electrophoretic deposition of biomaterial. J R Soc Interface 2010; 5: S581-613.

31. Lacefield WR. Current status of ceramic coatings for dental implants. Implant Dent 1998; 7: 315-20.

32. Sena AD, Andrade CD, Rossi M, Soares D. Hydroxyapatite deposition by electrophoresis on titanium sheets with different surface finishing. J Biomed Mater Res 2002; 60: $1-7$.

33. Ducheyne P, Qiu, Q. Bioactive Ceramics: The effect of surface reactivity on bone formation and bone cell function. J Biomater 1999; 20: 2287-303.

34. Manjubala I, Sastry TP, Kumar RV. Bone in-growth induced by biphasic calcium phosphate ceramic in femoral defect of dogs. J Biomater Appl 2005; 19: 341-60.

35. Yang GL, He FM, Song E, Hu JA, Wang XX, Zhao SF. In vivo comparison of bone formation on titanium implant surfaces coated with biomimetically deposited calcium phosphate or electrochemically deposited hydroxyapatite. Int J Oral Maxillofac Implants 2010; 25: 669-80. 